\title{
Criação e Destruição de Empregos no Setor Primário no Brasil entre 2000 e 2009
}

\author{
Flavio Kaue Fiuza-Moura ${ }^{3}$, Carina Diane Nakatani-Macedo ${ }^{4}$, \\ Marcia Regina Gabardo da Camara ${ }^{5}$ e Umberto Antonio Sesso Filho ${ }^{6}$
}

Resumo: O objetivo do presente artigo é analisar a variação de emprego no setor primário nos anos 2000-2009 para o Brasil. Utiliza-se a metodologia de insumo-produto por meio da decomposição estrutural da variação do emprego em efeitos intensidade, tecnologia, estrutura da demanda final, volume da demanda final e efeito total. Os principais resultados mostraram que, no período de análise, houve decréscimo de 773 mil vagas para o setor primário. Conclui-se que os subsetores de agricultura, silvicultura e exploração florestal, e pecuária e pesca foram os principais responsáveis pela queda do emprego por meio do efeito de intensidade. No efeito total, conclui-se que houve aumento significativo de vagas de trabalho nos subsetores de petróleo e gás natural (170\%) e minério de ferro (96\%); porém, não suficiente para resultar em variação positiva no saldo total, dado que a participação destes setores é pouco expressiva no total de vagas de emprego do setor primário.

Palavras-chaves: Tecnologia, emprego, insumo-produto.

Abstract: The objective of this paper is to analyze the employment variation in primary sector between the years 2000-2009 in Brazil. We used the methodology of input-output through the structural decomposition of the employment variation divided into effects of employment intensity, technology, demand structure, demand growth and total net variation. The main results showed that between the periods studied, there was a decrease of 773 thousand jobs in the sector of Agriculture and Extraction. We also find that the Agriculture, Forestry and Lumbering, and Livestock and Fishing sectors were the responsible for the employment decrease through the intensity effect. Looking at the

DOI - http://dx.doi.org/10.1590/1234-56781806-94790550108

1. Os autores agradecem ao Nereus (Núcleo de Economia Regional e Urbana) da Faculdade de Economia e Administração da USP por disponibilizar as matrizes insumo-produto utilizadas neste estudo, aos pareceristas ad hoc e à equipe editorial da Revista de Economia e Sociologia Rural pelos comentários e sugestões. Quaisquer erros remanescentes são de nossa inteira responsabilidade.

2. Data de submissão: 19 de abril de 2016. Data de aceite: 2 de dezembro de 2016.

3. Universidade de São Paulo, São Paulo, Brasil. E-mail: fiuzamoura@usp.br

4. Universidade de São Paulo, Piracicaba, São Paulo, Brasil. E-mail: nakatanicarina@gmail.com

5. Universidade Estadual de Londrina. Londrina, Paraná, Brasil. E-mail: mgabardo@uel.br

6. Universidade Estadual de Londrina, Londrina, Paraná, Brasil. E-mail: umasesso@uel.br 
total job variation, we found out that a significant amount of jobs were created in the Oil and Natural Gas and Iron sectors. Despite of that, and mostly because these sectors have a minor participation in the Brazilian primary sector, this employment increase was not enough to counterbalance the job decrease in the other sectors.

Key-words: Technology, employment, input-output.

Classificação JEL: Q16, J21, R15.

\section{Introdução}

A discussão sobre a tecnologia e seus efeitos sobre o mercado de trabalho e principalmente em relação aos níveis de emprego tem motivado estudos, segundo Mattoso (2000). O progresso técnico desemprega inicialmente, mas contribui no longo prazo para o incremento da produtividade e o crescimento econômico, pois a evolução tecnológica gera novos postos de trabalho, permitindo o deslocamento e a realocação dos empregados na segunda etapa (KATO e PONCHIROLLI, 2002). Mattoso (2000) e Rossi e Oliveira (2005) destacam que a teoria denominada "teoria do desemprego por adaptação" ou "desemprego de transição" vai de encontro aos argumentos normalmente observados entre os pesquisadores da área de Ciências Sociais, que tendem a argumentar que a tecnologia empregada pelo sistema capitalista leva à precarização do homem, à criação de postos secundários de trabalho e à desumanização (MATTOSO, 2000; ROSSI e OLIVEIRA, 2005).

Amorim, Coronel e Teixeira (2009) encontraram baixa capacidade de geração direta de empregos no setor agropecuário, apesar de este se mostrar como segmento produtivo chave para a economia nacional por ser grande demandante e fornecedor de insumos. Logo, o presente estudo procura verificar qual a influência do progresso técnico sobre a geração de empregos no setor primário.
O objetivo do artigo é analisar a variação de emprego no setor primário entre 2000 e 2009 para o Brasil e, para tanto, utiliza-se a metodologia de insumo-produto por meio da decomposição estrutural da variação do emprego em efeitos de intensidade do uso do fator emprego, tecnológico, estrutura demanda final, volume da demanda final e efeito total. O estudo busca medir os efeitos diretos e indiretos que uma elevação do progresso técnico tem sobre a geração de empregos no setor primário para o Brasil. A consecução do objetivo deste estudo por meio da metodologia aqui apresentada se justifica, pois, a despeito da existência de estudos similares para outros setores, não foram encontradas pesquisas que se aprofundassem na relação entre tecnologia e emprego especificamente no setor primário e que o fizesse por meio da análise de decomposição estrutural da variação do emprego.

O principal motivo para a escolha do período de análise de 2000 a 2009 é que, de acordo com o Censo de 2000, o número de pessoas ocupadas registradas foi de aproximadamente 65 milhões e, em 2009, esse número subiu para aproximadamente 86 milhões, resultando num crescimento de cerca de 21 milhões. Isto significa aumento de $31,57 \%$ da população ocupada na década. No setor primário, houve redução de $22,6 \%$ para $17,67 \%$ na participação da mão de obra total no mesmo período, segundo IBGE (2014) e Nereus (2014). 
Entre os estudos selecionados que discutem tecnologia e emprego e têm relação próxima com o estudo apresentado destacam-se Cacciamali e Bezerra (1997) e De Negri et al. (2006), que estes relacionam os ganhos de produtividade causados pela abertura comercial com as variações de emprego. Os estudos que utilizaram a ferramenta insumo-produto e enfocam a temática do presente estudo são de Sesso Filho et al. (2010), Ymai (2010) e Kupfer e Freitas (2004) e estes autores utilizaram métodos de decomposição estrutural para identificar as fontes da variação do emprego para todos os setores no Brasil para diferentes períodos de tempo. O presente estudo adota a metodologia utilizada em Sesso Filho et al. (2010) e Ymai (2010) para verificar as fontes de variação do emprego no setor primário nacional. Estudos similares acerca dos setores secundário e terciário podem ser encontrados em Nakatani-Macedo e outros (2015) e Fiuza-Moura e outros (2015).

Este trabalho está dividido em seis partes, incluindo esta introdução. Na segunda parte será abordada a teoria acerca da relação entre tecnologia e geração de empregos estabelecendo o debate sobre as duas principais vertentes conflitantes que abordam o assunto, bem como algumas evidências para o caso brasileiro. Na terceira, o setor primário no Brasil é abordado. Na quarta, será apresentada detalhadamente a metodologia de pesquisa adotada. Na quinta parte será feita a análise tabular dos resultados obtidos. Na sexta e última parte serão apresentadas as conclusões do estudo, suas limitações e possibilidades de estudos futuros.

\section{Tecnologia, produtividade e (des)emprego}

Kato e Ponchirolli (2002) afirmam que a tecnologia afeta negativamente o nível de emprego no curto prazo e que o progresso técnico muda a composição setorial e funcional da economia e do emprego e decorre o "desemprego transitório de adaptação". Para a teoria denominada de "desemprego transitório", a inserção de uma nova tecnologia poupadora de mão de obra causa demissões nas empresas beneficiadas pelo progresso e proporciona ganho de produtividade na economia como um todo, contribuindo para o crescimento econômico e a geração de um maior número de empregos no longo prazo. Tal efeito pode ser denominado de "geração de empregos indireta" por parte da evolução técnica.

Segundo Mattoso (2000), o progresso tecnológico acelera as transformações na organização, divisão técnica e qualificação do trabalho e altera sua distribuição setorial com relação a nascimento e destruição de novas atividades econômicas gerando a criação e destruição de ocupações. Embora seja a força motriz do processo de criação e destruição, o avanço técnico não determina, a priori, suas consequências quando a análise é agregada no quadro nacional. Logo, não é possível afirmar que ganhos de produtividade levam a maior desemprego para todos os casos e em todas as situações.

De acordo com Rossi e Oliveira (2005), a tecnologia é o conjunto de processos utilizados no sistema produtivo, e uma das principais características desse progresso técnico é ser poupador de mão de obra no curto prazo. Porém, a "teoria da compensação" afirma que tal efeito negativo direto é compensado e muitas vezes superado pela geração indireta de empregos causada pelo aumento da produtividade e consequente expansão econômica no longo prazo. As evidências comprovando esta teoria parecem não ser muito claras, dado que há exemplos de países desenvolvidos com altas taxas de desemprego estrutural, enquanto que, em outros países com o mesmo nível de desenvolvimento, são observadas taxas de desemprego mais baixas. A validade da compensação do desemprego tecnológico por meio de maior expansão econômica parece ser objeto de avaliação empírica, caso a caso.

No caso brasileiro, foram identificados alguns estudos que abordaram os efeitos do progresso técnico na economia e no desemprego no Brasil. Cacciamali e Bezerra (1997) estudaram os efeitos da abertura comercial entre 1991 e 1995 na indústria nacional e verificaram que os ganhos 
de produtividade causados pela necessidade de progresso técnico gerado pela abertura comercial foram os grandes causadores do aumento da taxa de desemprego no País.

A relação entre tecnologia e emprego nos setores de comércio e serviços foi discutida recentemente no artigo de Fiuza-Moura et al. (2015) que, a partir da análise de decomposição estrutural da variação do emprego, verificaram que a tecnologia aumenta o volume de emprego no setor de serviços e desemprego no comércio, enquanto Nakatani-Macedo et al. (2015), também por meio da técnica de decomposição estrutural da variação do emprego, comprovaram que a tecnologia gerou emprego na indústria brasileira no período de 2000 a 2009.

\section{O setor primário no Brasil}

Sandroni (1999) classifica as atividades produtivas em três setores básicos na economia de um país de acordo com a formulação proposta originariamente por Colin Clark. O setor primário reúne as atividades agropecuárias e extrativas (vegetais e minerais). O setor secundário engloba a produção de bens físicos por meio da transformação de matérias-primas realizada pelo trabalho humano com o auxílio de máquinas e ferramentas: inclui toda a produção fabril, a construção civil e a geração de energia. O setor terciário abrange os serviços em geral: comércio, armazenagem, transportes, sistema bancário, saúde, educação, telecomunicações, fornecimento de energia elétrica, serviços de água e esgoto e administração pública. A importância relativa de cada um desses setores no produto total da economia de um país é bastante variável e determina o grau de desenvolvimento econômico de uma nação. Segundo o autor, em economias subdesenvolvidas predominam as atividades primárias.

De acordo com Figueiredo (2004), a agricultura sempre foi vista como de grande importância para o crescimento econômico de um país e tratada como tópico recorrente entre os economistas. Em países em desenvolvimento, como o Brasil, a agricultura pode ser entendida como peça fundamental para a alavancagem do crescimento. A autora utilizou a metodologia de insumo-produto para analisar o setor de agropecuária no estado de Mato Grosso comparando-o com o resto do Brasil com base nas matrizes das contas nacionais de 1999. Seus resultados indicaram elevada influência do setor agropecuário como demandante e fornecedor de insumos, tanto no estado analisado como no restante do País.

Com relação à geração de empregos para o estado e para o Brasil, os setores primários se mostraram de baixa relevância com relação à geração direta de ocupações; porém, com elevada geração indireta e induzida. Em relação à geração de renda, os setores indicaram baixa influência direta, sendo que seus impactos indiretos e induzidos (principalmente relacionados com o consumo das famílias) apresentaram valores significativamente mais elevados. Ao mesmo tempo, os multiplicadores de produção se mostraram elevados indicando grande influência dos setores para a geração do PIB nacional. Alinhando tais resultados, pode-se concluir que o setor primário, tanto para o estado de Mato Grosso quanto para o Brasil, apresenta maior influência indireta com relação a emprego e renda (é capaz de gerar mais empregos nos setores secundário e terciário) e tem grande importância para a dinamização e geração de riqueza para a economia.

Amorim, Coronel e Teixeira (2009) utilizam a metodologia de insumo-produto para analisar, em 2005, o comportamento de todos os setores da economia, visando inferir qual a importância de cada um deles como demandante e fornecedor de insumos e gerador de empregos, produto e renda. Seus resultados indicam que a agropecuária e indústria extrativa mineral são setores-chaves, pois possuem elevados índices de ligação para frente (elevado grau de fornecimento de insumos para demais setores) e elevados índices de ligação para trás (elevado grau de consumo de insumos dos demais setores). Portanto, estes são de grande importância para a dinamização da economia nacional. No mesmo 
estudo, os autores encontraram também o setor agropecuário com baixa capacidade de geração direta de emprego e fraca geração de renda. Por outro lado, os principais demandantes de seus insumos, a saber, indústrias extrativa mineral e de transformação, apresentaram elevados índices de multiplicação de renda e emprego.

Ao realizar a análise conjunta de ambos os resultados, pode-se interpretar que à medida que o setor primário avança tecnologicamente, se tornando mais intensivo em capital e elevando a produtividade de sua mão de obra, é demandado número menor de pessoas em tais setores. Ao mesmo tempo, eleva-se a demanda de insumos e trabalhadores por outros segmentos. Em outras palavras, ocorre uma migração de postos de trabalho do setor primário para os demais. A partir destes argumentos pode-se entender que o setor primário no Brasil é de grande importância para a economia nacional. Tais setores representaram, em 2009, 7,45\% do PIB (NEREUS, 2014).

Na Tabela 1 observa-se a participação no PIB e a participação da população ocupada no setor primário no Brasil em 2000 e 2009. Percebe-se que o setor de agricultura, silvicultura e exploração florestal representava 3,63\% do PIB em 2000 e aumentou para 3,81\% em 2009. No entanto, houve diminuição da participação na população ocupada em cerca de três pontos percentuais $(15,40 \%$ para $12,14 \%)$ entre os períodos. Os setores de pecuária e pesca e outros da indústria extrativa apresentaram queda tanto na participação no PIB quanto na participação na população ocupada no mesmo período. Os setores de petróleo e gás natural e minério de ferro apresenta- ram aumento na participação relativa no PIB com mesma tendência na participação na população ocupada. Com relação à população ocupada, apenas os setores de petróleo e gás natural e minério de ferro aumentaram a participação no período de análise, porém, com representatividades relativamente pequenas na população ocupada.

De 2000 a 2009, o quadro geral dos setores apresentou elevação na participação relativa do PIB de 7,2\% para 7,45\% (crescimento de 3,47\%) e redução relativa na participação da população ocupada de $22,6 \%$ para $17,67 \%$ (redução de $22 \%$ ). Tal fenômeno de redução de postos de trabalho não é caso recente, pois ao longo do século passado o setor primário deixou de ser o maior em termos de geração de renda e emprego, uma vez que o processo de desenvolvimento da economia brasileira levou a uma rápida urbanização. Porém, o setor ainda desempenha seu papel como grande fornecedor de insumos. As últimas décadas apresentaram intensa modificação tecnológica por meio do uso de máquinas agrícolas, agrotóxicos, fertilizantes e disseminação do uso de sementes geneticamente modificadas (FIGUEIREDO, 2004).

O Quadro 1 apresenta um compilado de alguns trabalhos empíricos recentes que tratam das mudanças estruturais, tecnológicas e do emprego na economia brasileira, incluindo resultados sobre o setor primário. Os trabalhos encontrados que fazem uso da metodologia de decomposição estrutural da variação do emprego dão pouca ênfase ao setor primário, enquanto que os trabalhos que abordam esta temática em específico não empregam métodos relacionados à

Tabela 1. Participação do setor primário no PIB e na população ocupada do Brasil (2000 e 2009)

\begin{tabular}{lcccc}
\hline \multicolumn{1}{c}{ Setores } & \multicolumn{2}{c}{ PIB (\%) } & \multicolumn{2}{c}{ População ocupada (\%) } \\
\cline { 2 - 5 } & 2000 & 2009 & 2000 & 2009 \\
\hline Agricultura, silvicultura e exploração florestal & 3,63 & 3,81 & 15,40 & 12,14 \\
Pecuária e pesca & 1,97 & 1,82 & 6,90 & 5,22 \\
Petróleo e gás natural & 1,01 & 1,06 & 0,03 & 0,07 \\
Minério de ferro & 0,28 & 0,52 & 0,02 & 0,04 \\
Outros da indústria extrativa & 0,31 & 0,25 & 0,25 & 0,20 \\
Total & 7,20 & 7,45 & 22,60 & 17,67 \\
\hline
\end{tabular}

Fonte: Elaborada pelos autores a partir dos dados IBGE (2014) e Nereus (2014). 


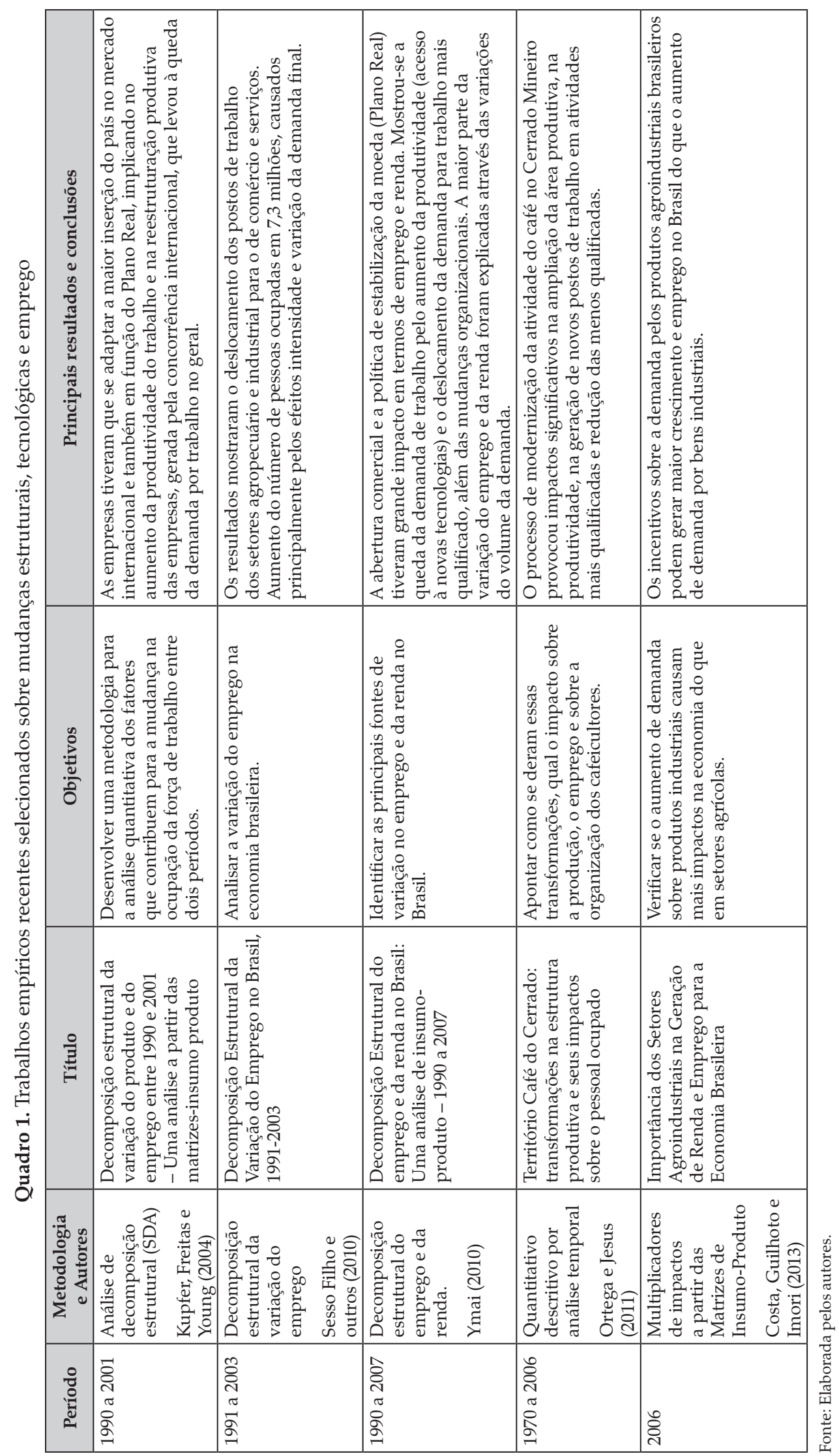


análise de insumo-produto e, quando empregam, não realizam a análise de decomposição estrutural da variação do emprego, evidenciando uma lacuna a ser preenchida na literatura nacional.

Uma vez considerados os argumentos acima, a compreensão do grau de participação do setor primário no número de pessoas ocupadas e geração de renda e constatada a escassez de estudos sobre o tema que utilizam a ferramenta insumo-produto, torna-se de grande interesse e importância entender como a tecnologia leva à criação e à destruição de postos de trabalho no setor primário brasileiro. Além disso, o presente estudo avança no tempo para a análise do período 20002009, utilizando o método da decomposição estrutural de insumo-produto mais recente.

A metodologia de decomposição estrutural tem sido utilizada para identificar as fontes de variação do emprego no Brasil. Sesso Filho e outros (2010) utilizaram a Análise de Decomposição Estrutural para mostrar a variação do emprego no Brasil no período 1993 a 2003. Os autores verificaram que houve um deslocamento dos postos de trabalho dos setores agropecuário e indústria para comércio e serviços com aumento do número total de pessoas ocupadas em 7,30 milhões. As mudanças foram causadas principalmente pelos efeitos intensidade de emprego, com menos 16,62 milhões de vagas, e estrutura da demanda final, com aumento de 20,85 milhões de vagas. Eles encontraram as maiores variações entre 1994 e 1995.

Ymai (2010) procurou identificar, por meio da metodologia de análise de decomposição estrutural, as principais fontes de variação no emprego e da renda a partir de 1990 no Brasil. O autor destacou as mudanças ocasionadas pela alteração tecnológica e o impacto desta alteração no emprego. $\mathrm{O}$ autor concluiu que a maior parte da variação do emprego e da renda são explicadas através das variações do volume da demanda.

Kupfer e Freitas (2004) analisaram a evolução do emprego no Brasil durante a década de 1990 utilizando o modelo de insumo-produto para decomposição da variação do produto e do emprego, e verificaram expansão de 5 milhões de postos de trabalho na década de 1990. Neste período, os autores constataram que as empresas tiveram que se adaptar ao novo cenário econômico decorrente da maior inserção do País no mercado internacional e também em função do Plano Real, o que implicou no aumento da produtividade do trabalho e reestruturação produtiva das empresas gerada pela concorrência internacional. Os fatos levaram à queda da demanda por trabalho na economia.

\section{Metodologia}

No presente artigo utiliza-se a metodologia de Sesso Filho e outros (2010) e Haan (2001) para realizar a Análise de Decomposição Estrutural e mostrar a variação do emprego no setor primário no Brasil. Nesta seção serão descritos resumidamente os principais pontos acerca da metodologia utilizada no artigo. Na primeira parte, realiza-se uma revisão sobre a teoria básica de Insumo-Produto. Na segunda, apresenta-se informações relacionadas à forma como foram obtidos e tratados os dados que serão utilizados para a realização da presente pesquisa.

\subsection{Insumo-Produto: a teoria}

Para compreender a Teoria de Insumo-Produto é necessário realizar a menção de Wassily Leontief (economista russo). Segundo o autor, é um sistema simples, que descreve e serve para interpretar operações econômicas em termos de relações estruturais básicas observáveis.

Segundo Leontief (1983), o esquema insumo-produto deriva da ideia de que cada produto pode ser entendido como um insumo, na medida em que o mesmo é aproveitado em outro setor da cadeia produtiva; desta forma, compras e vendas são equivalentemente observáveis. Partindo desta afirmação é possível montar esquemas de entradas e saídas que forneçam informações econômicas instrumentalizáveis. Para Leontief, tal instrumento de estudo gera segurança na medida em que se gera conhecimentos empíricos. 
A matriz insumo-produto é o fundamento central da obra de Leontief; este método de análise explica o funcionamento de uma economia e de sua estrutura com objetivo de dar clareza ao planejamento e desenvolvimento econômico.

O trabalho de Guilhoto (2000) mostra que, a partir de uma fotografia econômica obtida através da matriz de insumo-produto, pode-se mostrar como os setores estão relacionados entre si, desta forma observar quais setores suprem e demandam. Observando tal dinâmica, pode-se compreender como a economia funciona e como se dá a dependência entre os setores.

Para obter o sistema de insumo-produto, define-se a seguinte equação:

$$
X=(I-D B)^{-1} Y
$$

A equação 1 refere-se ao enfoque setor $(X)$ por setor $(Y)$ com a tecnologia baseada na indústria. Nesta equação, $X$ representa o vetor de produção setorial, $B$ representa a matriz de coeficientes técnicos de cada setor em relação a cada produto utilizado como insumo. $D$ determina a proporção, para cada produto, dos setores que o produzem. Temos que $Y$ representa o vetor da demanda final setorial e $X$ o vetor de produção. Este foco, na tecnologia baseada na indústria, é o que mais se aproxima do modelo original de Leontief e, portanto, é o padrão que se costuma utilizar para transformar as matrizes de produção e de usos e recursos no modelo de Leontief. Dada a matriz inversa de Leontief, $S=(I-A)^{-1}$, percebe-se que a matriz $D B$ seria equivalente à matriz $\mathrm{A}$ de coeficientes técnicos. $(I-A)^{-1}$ é a matriz de coeficientes diretos e indiretos. Desta forma, o elemento $S_{i j}$ deve ser interpretado como sendo a produção total do setor $i$ que é necessária para produzir uma unidade de demanda final do setor $j$.

Algumas limitações da análise podem ser apontadas de acordo com os pressupostos em que se baseiam a teoria insumo-produto, entre elas as afirmações de que existe um equilíbrio geral da economia a um dado nível de preços; a inexistência de ilusão monetária dos agentes econômicos; os retornos constantes à escala; os preços constantes e supõe-se que as mudanças tecnológicas são lentas e que todos os bens e serviços incluídos na matriz apresentam uma oferta infinitamente elástica, ou seja, toda a demanda adicional será coberta expandindo-se a produção aos custos representados na matriz (MIERNYK, 1974; GUILHOTO, 2000). Retornos constantes de escala indicam que as funções são homogêneas de grau um.

\subsection{Análise de decomposição}

O objetivo de análise é identificar as causas das variações do emprego em um determinado intervalo de tempo. Duas técnicas são capazes de identificar diversos fatores que influenciam as variáveis econômicas de interesse: a Análise de Decomposição de Índice (Index Decomposition Analysis - IDA) e a Análise de Decomposição Estrutural (Structural Decomposition Analysis SDA). As duas técnicas se assemelham e podem ser usadas para distinguir como mudanças setoriais, avanços tecnológicos e crescimento econômico provocam variações nas variáveis econômicas e ambientais.

A SDA utiliza dados oriundos das matrizes de insumo-produto com maior detalhamento da estrutura da economia que a IDA, pois esta utiliza apenas informações agregadas da economia limitadas aos níveis setoriais. Portanto, a IDA requer um número menor de dados que a SDA. Hoekstra e Bergh (2003) destacam que isto pode ser uma vantagem, considerando que facilita sua aplicação, e uma desvantagem, porque fornece informações menos detalhadas da estrutura da economia. O uso da SDA torna possível mensurar os efeitos estrutura e volume da demanda final sobre a variação do fator analisado, mas a IDA não apresenta estes efeitos.

\subsubsection{Formulação matemática do modelo Análise de Decomposição Estrutural (SDA)}

Wier e Hasler (1999) aplicaram a SDA para a Dinamarca trabalhando com emissões de nitrogênio, e o modelo adotado está descrito abaixo: 


$$
N_{t}=w_{t}\left(I-A_{t}\right)^{-1} D_{t} d_{t}
$$

em que $N_{t}$ é um escalar com as emissões de $N$; $w_{t}$ é um vetor de emissões por unidade de produção; $\left(I-A_{t}\right)^{-1}$ é a matriz inversa de Leontief; $D_{t}$ é matriz que apresenta, para cada um dos componentes da demanda final, as respectivas participações das demandas por setores e $d_{t}$ é um vetor com o nível absoluto de cada categoria da demanda final. Este modelo é um exemplo de que a metodologia da SDA pode ser aplicada tanto na análise das emissões de $\mathrm{CO}_{2}$, fontes de energia e em pesquisas referentes ao padrão de comércio internacional, estrutura e o crescimento da economia e ao mercado de trabalho. O modelo usado por eles é muito semelhante ao adotado por Haan (2001) e que foi empregado neste trabalho. Caso o modelo fosse aplicado para o Brasil com dados de 2009, teríamos: $w_{t}$ é um vetor linha com 55 valores com emissões por unidade de produção dos setores; $\left(I-A_{t}\right)^{-1}$ é a matriz inversa de Leontief (55x55); $D_{t}$ é matriz que apresenta, para cada um dos componentes da demanda final, as respectivas participações das demandas por setores (55x5); $d_{t}$ é um vetor (5x1) com o nível absoluto de cada categoria da demanda final; o índice $t$ se refere ao ano de aplicação do modelo e seus dados.

Devido à sua estrutura matemática, a metodologia SDA pode ser utilizada para análise de qualquer informação setorial dada pela matriz de uso, tais como impostos, valor adicionado, importações e salários. A decomposição estrutural foi a metodologia empregada por Kupfer e Freitas (2004) para estudar a variação do emprego no País para o período 1990-2001.

A seguir será detalhada a formulação matemática do método SDA que foi utilizada no desenvolvimento deste trabalho. $\mathrm{O}$ modelo que mais atendeu a proposta do artigo é baseado em Haan (2001) com aplicação ao mercado de trabalho. Os trabalhos que se utilizam do modelo de Análise de Decomposição Estrutural usam o modelo de insumo-produto de Leontief como base para a decomposição, pois este permite uma melhor aproximação da realidade considerando- -se que variações no emprego seguem uma função linear do crescimento econômico.

As mudanças no emprego por setor $(\Delta c)$ podem ser descritas como função do crescimento econômico em termos de ganho ou não de eficiência. Já as mudanças no emprego em termos de unidades monetárias de produto são determinadas por $(\Delta n)$, que significa eficiência do trabalho ou intensidade de emprego. Mudanças nos coeficientes técnicos da economia, mudanças na composição da estrutura da demanda final e o aumento do volume na demanda final podem ser denominadas respectivamente por $(\Delta s),\left(\Delta y^{s}\right)$ e $\left(\Delta y^{v}\right)$. Com isso, a fórmula genérica para cálculo da decomposição dos fatores pode ser caracterizada por:

$$
\Delta c=\Delta n+\Delta s+\Delta y^{s}+\Delta y^{v}
$$

Assim, a decomposição que se refere aos anos de 2000 e 2009 resulta em quatro diferentes expressões, correspondendo cada uma aos fatores das mudanças estruturais na economia brasileira.

A análise da decomposição estrutural com relação ao número de postos de trabalho pode ser derivada da seguinte forma: suponha que $c_{1 j}$ de $C$ representa o número de empregos da atividade $j$. Desta maneira, o total de empregos gerados por todas as atividades produtivas pode ser determinado como uma função do produto total:

$$
c=N X
$$

O elemento $c$ indica o valor total de empregos gerados em todas as atividades produtivas. O vetor coluna $X$ possui os valores do produto setorial total e $N=C \hat{X}^{-1}$, em que os elementos $n_{1 j}$ de $N$ indicam os coeficientes de emprego, ou seja, a quantidade de empregos gerada por uma unidade monetária de produção da atividade $j . \hat{X}$ representa a matriz diagonalizada de $X$, este é um vetor que possui os valores da produção setorial. A equação $X=(I-A)^{-1} y$ mostra o valor da produção setorial total como função da demanda final, sendo que $S=(I-A)^{-1}$ representa a matriz inversa de Leontief e $A$ representa a matriz de coeficientes técnicos. 
A matriz com os valores dos componentes da demanda final, $y$, com dimensão $55 \times 5$ contém os elementos da demanda final: exportação, consumo das instituições civis sem fins lucrativos, formação bruta de capital fixo, consumo da administração pública e consumo das famílias. Os valores setoriais de variação de estoques foram somados ao consumo das famílias porque o modelo não considera valores negativos, o que pode ocorrer no componente variação de estoques e este somatório anula possíveis valores abaixo de zero. Tem-se cinco componentes da demanda final. O total na linha dessa matriz é o vetor linha $y^{v}$, que é o volume da demanda final com dimensão (5x1). A composição da demanda final, $y^{\text {s }}$, é uma matriz de coeficientes obtida pela divisão de cada elemento da matriz pelo vetor $y^{v}$ na sua forma inversa e diagonalizada:

$$
y^{s}=y \hat{y}^{v-1}
$$

Posto isso, os empregos gerados por todas as atividades produtivas podem ser determinados pela seguinte equação:

$$
c=N X=N S y^{s} y^{v}
$$

em que para o caso deste trabalho: $N$ é o vetor (1x55) de coeficientes de emprego; $S$ é a matriz (55x55) inversa de Leontief; $y^{s}$ é a matriz (55x5) de coeficientes da demanda final; $y^{v}$ é o vetor (5x1) com o total da demanda final por categoria.

A decomposição estrutural da mudança no uso do fator trabalho e número de empregos entre os períodos de 2000 e 2009 podem ser determinados como se segue:
De acordo com Dietzenbacher e Los (2000), a formulação feita na equação 7 descreve apenas uma situação dentre várias outras possíveis. Desta maneira, com $n$ fatores poderão ocorrer $n$ ! formas de decomposição estrutural que segue uma estrutura similar à descrita acima. Jacobsen (2000) e Hoem (2003) utilizaram em seus estudos, como resultado de cada componente da decomposição, a média das duas formas polares existentes. A equação 7 é uma das formas polares. A outra é dada por:

$$
\begin{aligned}
\Delta c= & (\Delta N) S_{(t-1)} y_{(t-1)}^{s} y_{(t-1)}^{v}+ \\
& +N_{(t)}(\Delta S) y_{(t-1)}^{s} y_{(t-1)}^{v}+ \\
& +N_{(t)} S_{(t)}\left(\Delta y^{s}\right) y_{(t-1)}^{v}+ \\
& +N_{(t)} S_{(t)} y_{(t)}^{s}\left(\Delta y^{v}\right)
\end{aligned}
$$

Aqui também é utilizada a sugestão de Jacobsen (2000) e a média das duas formas polares é dada por:

$$
\Delta c=1 / 2\left((\Delta N) S_{(t)} y_{(t)}^{s} y_{(t)}^{v}+(\Delta N) S_{(t-1)} y_{(t-1)}^{v}\right)
$$

(Efeito intensidade de emprego)

$$
+1 / 2\left(N_{(t-1)}(\Delta S) y_{(t)}^{s} y_{(t)}^{v}+N_{(t)}(\Delta S) y_{(t-1)}^{s} y_{(t-1)}^{v}\right)
$$

(Efeito tecnológico)

$$
+1 / 2\left(N_{(t-1)} S_{(t-1)}\left(\Delta y^{s}\right) y_{(t)}^{v}+N_{(t)} S_{(t)}\left(\Delta y^{s}\right) y_{(t-1)}^{v}\right)
$$

(Efeito estrutura da demanda final)

$$
+1 / 2\left(N_{(t-1)} S_{(t-1)} y_{(t-1)}^{s}\left(\Delta y^{v}\right)+N_{(t)} S_{(t)} y_{(t)}^{s}\left(\Delta y^{v}\right)\right)
$$

(Efeito volume da demanda final)

$$
\begin{aligned}
& \Delta c=c_{(t)}-c_{(t-1)} \\
& \Delta c=N_{(t)} S_{(t)} y_{(t)}^{s} y_{(t)}^{v}-N_{(t-1)} S_{(t-1)} y_{(t-1)}^{s} y_{(t-1)}^{v} \\
& \Delta c=(\Delta N) S_{(t)} y_{(t)}^{s} y_{(t)}^{v}+N_{(t-1)} S_{(t)} y_{(t)}^{s} y_{(t)}^{v}-N_{(t-1)} S_{(t-1)} y_{(t-1)}^{s} y_{(t-1)}^{v} \\
& \Delta c=(\Delta N) S_{(t)} y_{(t)}^{s} y_{(t)}^{v}+N_{(t-1)}(\Delta S) y_{(t)}^{s} y_{(t)}^{v}+N_{(t-1)} S_{(t-1)} y_{(t)}^{s} y_{(t)}^{v}-N_{(t-1)} S_{(t-1)} y_{(t-1)}^{s} y_{(t-1)}^{v} \\
& \Delta c=(\Delta N) S_{(t)} y_{(t)}^{s} y_{(t)}^{v}+N_{(t-1)}(\Delta S) y_{(t)}^{s} y_{(t)}^{v}+N_{(t-1)} S_{(t-1)}\left(\Delta y^{s}\right) y_{(t)}^{v}+N_{(t-1)} S_{(t-1)} y_{(t-1)}^{s} y_{(t)}^{v}-N_{(t-1)} S_{(t-1)} y_{(t-1)}^{s} y_{(t-1)}^{v} \\
& \Delta c=(\Delta N) S_{(t)} y_{(t)}^{s} y_{(t)}^{v}+N_{(t-1)}(\Delta S) y_{(t)}^{s} y_{(t)}^{v}+N_{(t-1)} S_{(t-1)}\left(\Delta y^{s}\right) y_{(t)}^{v}+N_{(t-1)} S_{(t-1)} y_{(t-1)}^{s}\left(\Delta y^{v}\right)
\end{aligned}
$$


Para obter os resultados desagregados por setor basta tomar $N$ na sua forma diagonalizada na equação 6, $C=\hat{N} X=\hat{N} S y_{(t)}^{s} y_{(t)}^{v}$. Para o presente estudo temos que $t$ se refere a 2009 e $t-1$, a 2000.

\subsubsection{Fontes dos dados}

Os dados utilizados neste estudo para compor as matrizes insumo-produto são das Contas Nacionais divulgados pelo Instituto Brasileiro de Geografia e Estatística (IBGE, 2014) do período de 2000 e 2009 e também dados obtidos através dos estudos realizados pelo Núcleo de Economia Urbana e Regional da USP - Nereus (2014). As matrizes utilizadas possuem 56 setores, mas os cálculos são realizados retirando-se o setor "Serviços domésticos" que apresenta linha e coluna de zeros na matriz de insumo-produto. Este setor refere-se a domicílios que possuem empregados.

\subsubsection{Deflacionamento dos valores das matrizes de insumo-produto}

O cálculo realizado na decomposição estrutural requer que todos os dados de valores monetários estejam em uma unidade padrão para que os resultados obtidos possam ser comparados ao longo do tempo, excluindo, assim, desvios provocados pelas mudanças monetárias, cortes de zero e variação no nível de preços. Os dados das matrizes são expressos em moeda corrente; portanto, para este trabalho realizou-se a deflação dos dados de 2000 e 2009 adotando 2009 como ano-base. As matrizes disponibilizadas pelo Núcleo de Economia Urbana e Regional da USP - Nereus (2014), estimadas a partir da metodologia de Guilhoto e Sesso Filho (2005) e Guilhoto e Sesso Filho (2010), apresentam as matrizes de insumo-produto do Brasil a preços básicos. O deflator utilizado foi o deflator implícito setorial obtido junto ao IBGE (2009) que traz a varia- ção percentual anual do nível de preços em cada setor. A partir dessa variação elabora-se um índice de preços capaz de transformar todos os valores monetários correntes de 2000 em valores constantes de 2009. Para o deflacionamento basta multiplicar cada valor corrente pelo deflator em índice do setor correspondente.

\section{Análise de resultados}

A Tabela 2 apresenta a decomposição da variação do emprego para os três grandes setores da economia nacional. Nota-se que o resultado geral foi positivo, dado que 17,675 milhões de novas vagas de emprego surgiram no período.

O setor primário teve queda de 7,706 milhões de vagas em função do efeito intensidade de emprego, que é causado pela mudança no nível de uso do fator trabalho. Para o mesmo setor, o efeito tecnológico, que indica o efeito das variações na composição dos insumos intermediários, teve ganho de 1,152 milhão de vagas de trabalho. O efeito estrutura da demanda, que é causado pelas variações na estrutura da demanda final, obteve acréscimo próximo de 2 milhões de novas vagas de trabalho. E, por último, o efeito do volume da demanda final mostrou aumento de 3,8 milhões de vagas de trabalho. O resultado total mostra a destruição de 773 mil postos de trabalho no setor primário, indicando migração de ocupações para os demais grandes setores. $\mathrm{O}$ setor secundário apresentou variação positiva de 4,3 milhões de vagas de trabalho no período, o que equivale a $25 \%$ do total das vagas geradas. De acordo com Nakatani-Macedo e outros (2015), em estudo sobre o segundo setor, os autores destacam que, dentre os setores que compõem o setor secundário, os de alimentos e bebidas, artigos do vestuário e acessórios e construção civil estão entre os que apresentaram maior crescimento relativo no número de empregos. 
Tabela 2. Decomposição estrutural da variação do emprego dos setores no Brasil (2000-2009)

\begin{tabular}{lccccc}
\hline \multirow{2}{*}{ Setores } & \multicolumn{5}{c}{ Variação do emprego por tipo de efeito* } \\
\cline { 2 - 6 } & $\begin{array}{c}\text { Intensidade de } \\
\text { emprego }\end{array}$ & Tecnológico & $\begin{array}{c}\text { Estrutura da } \\
\text { demanda final }\end{array}$ & $\begin{array}{c}\text { Volume da } \\
\text { demanda final }\end{array}$ & Total \\
\hline Setor primário & -7706 & 1152 & 1911 & 3870 & -773 \\
Setor secundário & 2825 & -844 & -1378 & 3785 & 4388 \\
Setor terciário & -502 & 70 & 2946 & 11546 & 14060 \\
Total & -5383 & 378 & $\mathbf{3 4 7 9}$ & $\mathbf{1 9 2 0 1}$ & $\mathbf{1 7 6 7 5}$ \\
\hline
\end{tabular}

${ }^{*}$ Em milhares de empregos.

Fonte: Elaborada pelos autores a partir dos dados do IBGE (2014) e Nereus (2014).

No setor terciário houve acréscimo de cerca de 14 milhões de vagas entre 2000 e 2009. Este volume corresponde a $79,54 \%$ do total das vagas (17,67 milhões) de trabalho geradas no período para o Brasil. Um estudo mais aprofundado sobre o terceiro setor pode ser encontrado em FiuzaMoura e outros (2016), em que os autores indicam que o efeito tecnológico criou empregos no setor de serviços e eliminou postos de trabalho no comércio.

A Tabela 3 mostra a decomposição estrutural do emprego por tipo de efeito para o setor primário desagregado nos subsetores que o compõem. $\mathrm{O}$ setor primário foi o único que apresentou redução do emprego quando comparado com os setores secundário e terciário. Tal queda foi num valor total de 773 mil vagas a menos em 2009 frente a 2000.

Observando-se a Tabela 3, nota-se que os subsetores com maior impacto negativo com relação ao efeito intensidade de emprego foram os de agricultura, silvicultura e exploração floresta e pecuária e pesca, com variações de -5,67 e -1,97 milhões de vagas de trabalho, respectivamente. Já para o efeito tecnológico observa-se tendência geral positiva, exceto para o setor de minério de ferro, que apresentou diminuição de 2 mil postos de trabalho. Para o efeito estrutura da demanda os únicos setores com resultados negativos para a geração de empregos foram os de petróleo e gás natural e, novamente, minério de ferro, com variações de -12 mil e -2 mil vagas de trabalho. Com relação ao efeito volume da demanda final, todos os setores tiveram desempenho positivo no que se refere à criação de novas vagas de trabalho, com acréscimo de 3,87 milhões de novos empregos.

No efeito total - líquido - os efeitos tecnológico, estrutura da demanda e volume da demanda não foram suficientes para contrabalancear o efeito intensidade de emprego para os setores agricultura, silvicultura e exploração florestal e pecuária e pesca, levando-os a apresentar saldo final negativo. Os demais setores apresentaram efeitos líquidos positivos; porém, em

Tabela 3. Decomposição estrutural da variação do emprego no setor primário no Brasil (2000-2009)

\begin{tabular}{|c|c|c|c|c|c|}
\hline \multirow[b]{2}{*}{ Setores } & \multicolumn{5}{|c|}{ Variação do emprego por tipo de efeito* } \\
\hline & $\begin{array}{c}\text { Intensidade de } \\
\text { emprego }\end{array}$ & Tecnológico & $\begin{array}{l}\text { Estrutura da } \\
\text { demanda final }\end{array}$ & $\begin{array}{c}\text { Volume da } \\
\text { demanda final }\end{array}$ & Total \\
\hline Agricultura, silvicultura e exploração florestal & -5.665 & 938 & 1.649 & 2.646 & -432 \\
\hline Pecuária e pesca & -1.972 & 140 & 266 & 1.165 & -402 \\
\hline Petróleo e gás natural & 10 & 33 & -12 & 9 & 40 \\
\hline Minério de ferro & 15 & -2 & -2 & 6 & 18 \\
\hline Outros da indústria extrativa & -94 & 43 & 11 & 43 & 2 \\
\hline Total & -7.706 & 1.152 & 1.911 & 3.870 & -773 \\
\hline
\end{tabular}

${ }^{*}$ Em milhares de empregos.

Fonte: Elaborada pelos autores a partir de dados IBGE (2014) e Nereus (2014). 
menor volume, resultando em destruição de 773 mil postos de trabalho.

É importante salientar que na primeira coluna (efeito intensidade) da Tabela 3, o valor de $-5,67$ milhões encontrado para o setor de agricultura, silvicultura e exploração florestal é muito maior em valor absoluto comparado às $15 \mathrm{mil}$ vagas do setor de minério de ferro. No entanto, $-5,67$ milhões equivalem a $-46,6 \%$ do total de vagas de emprego para este setor, que contava com 12,16 milhões de vagas em 2000. Para o setor de minério de ferro, as 15 mil vagas de emprego representam $79,9 \%$ do total das 18,77 mil vagas existentes em 2000 .

A Figura 1 mostra, em forma de radar, o impacto percentual causado pelo efeito intensidade de emprego nos postos de trabalho dos cinco setores que compõem o setor primário. $\mathrm{O}$ centro do gráfico equivale a um impacto negativo de $100 \%$ dos postos de trabalho existentes no ano 2000 enquanto que a fronteira do gráfico indica impacto positivo de $100 \%$.

$\mathrm{O}$ efeito intensidade negativo significa diminuição da relação emprego/produção e a interpretação é que houve aumento da produtividade do trabalho no período de análise para três dos cinco subsetores do setor primário. No caso da agricultura, silvicultura e exploração florestal, o aumento da produtividade do trabalho causaria o desemprego para 5,7 milhões de pessoas caso não ocorressem os efeitos tecnológico, estrutura da demanda final e volume da demanda final, que contribuíram positivamente para a geração de empregos neste subsetor primário. $\mathrm{O}$ efeito líquido foi de menos 432 mil empregos.

$\mathrm{O}$ aumento da produtividade do trabalho, mostrado como efeito negativo do efeito intensidade do uso do fator no cálculo da decomposição estrutural, indica que a tendência é de aumento da remuneração média e qualidade do trabalho. Devemos considerar também que trabalhadores do subsetor que tiveram queda do emprego seguiram para outras atividades econômicas, o que torna importante a requalificação profissional para estas pessoas.

A partir da Figura 1 verifica-se que os setores que mostraram geração de empregos são os de número 3 e 4 (petróleo e gás natural e minério de ferro) com $42,5 \%$ e $79,9 \%$, respectivamente. Enquanto que os que apresentaram impactos

Figura 1. Impacto percentual do efeito intensidade de emprego sobre os postos de trabalho do setor primário, no Brasil para o período 2000-2009

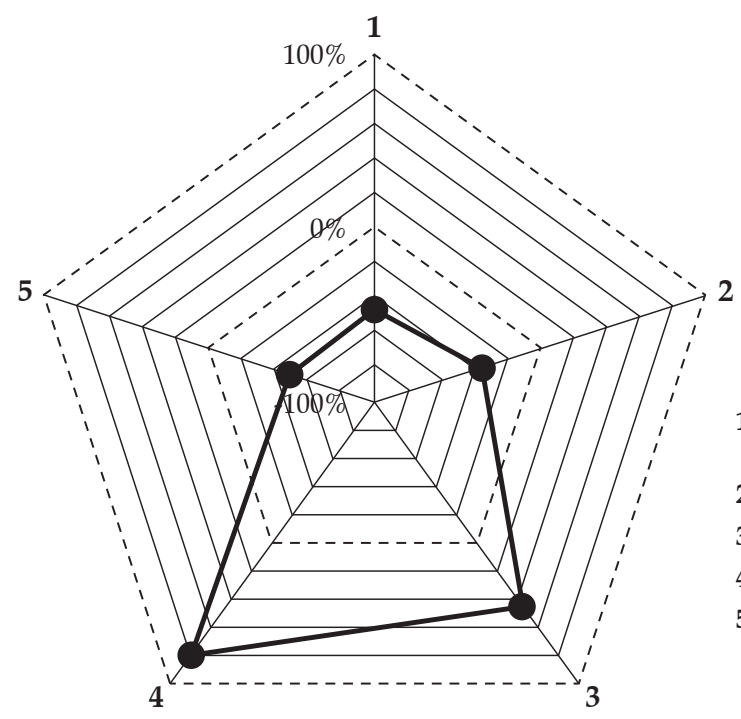

1 - Agricultura, silvicultura e exploração florestal

2 - Pecuária e pesca

3 - Petróleo e gás natural

4 - Minério de ferro

5 - Outros da indústria extrativa

Fonte: Elaborado pelos autores a partir dos dados IBGE (2014) e Nereus (2014). 
negativos foram os de número 1, 2 e 5 (agricultura, silvicultura e exploração florestal, pecuária e pesca e outros da indústria extrativa) com $-46,6 \%$, $-36,2 \%$ e $-48,6 \%$, respectivamente.

A Figura 2 apresenta o impacto percentual do emprego devido ao efeito tecnológico. Os setores que mostraram aumentos causados pelas mudanças tecnológicas foram os de número 1, 2, 3 e 5, sendo eles: agricultura, silvicultura e exploração florestal $(7,7 \%)$, pecuária e pesca $(2,6 \%)$, outros da indústria extrativa $(22,2 \%)$, com destaque para o setor de petróleo e gás que mostrou aumento de $140,4 \%$. No setor de petróleo e gás houve aumento de 33 mil vagas de trabalho, sendo que tal setor contava com 23,5 mil vagas no ano 2000 . $\mathrm{O}$ único setor impactado negativamente foi o de número 4 (minério de ferro), com destruição de 2 mil vagas de trabalho que correspondem a $-10,7 \%$ no montante de 18,77 mil vagas existentes em 2000 para este setor. O presente estudo corrobora os resultados de Costa, Guilhoto e Imori (2013), que analisaram os efeitos diretos e indiretos no emprego e renda de choques na demanda final e verificaram a criação de riqueza e emprego nos setores de soja, açúcar, etanol, abate de bovinos e aves, milho e arroz, em sua maioria derivados da expansão de área.

O efeito tecnológico mostra a modificação da combinação de insumos para a produção e seu impacto sobre o emprego setorial. Para o cálculo da decomposição estrutural é realizada a comparação das duas matrizes de coeficientes técnicos dos anos de 2000 e 2009, e o resultado mostra aumento do número de empregos por efeito tecnológico. Isto mostra que as cadeias produtivas do setor primário impactaram positivamente sobre a variável emprego. Houve aumento da demanda por insumos provenientes dos subsetores primários dentro das cadeias produtivas.

A Figura 3 indica o impacto percentual do emprego devido ao efeito estrutura da demanda final e vai de $100 \%$ a $-100 \%$.

A Figura 3 mostra mudanças na quantidade de vagas de trabalho causadas por mudanças estruturais na demanda final em valores percentuais. Os setores geradores de emprego para este efeito são os de número 1, 2 e 5 (agricultura, silvicultura e exploração florestal, pecuária e pesca e outros da indústria extrativa), com impactos de $13,6 \%, 4,9 \%$ e $5,7 \%$, respectivamante. Já o

Figura 2. Impacto percentual do efeito tecnológico sobre os postos de trabalho do setor primário, no Brasil para o período 2000-2009

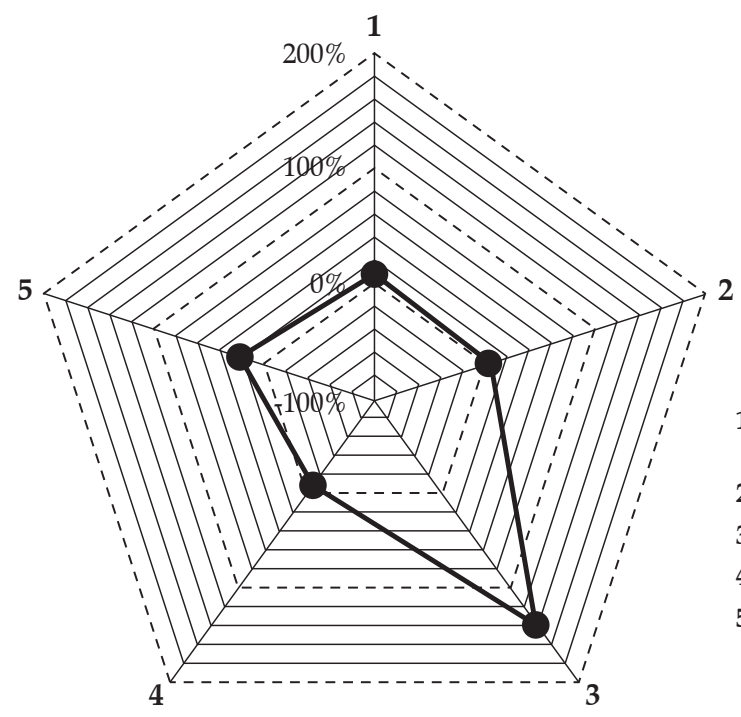

1 - Agricultura, silvicultura e exploração florestal

2 - Pecuária e pesca

3 - Petróleo e gás natural

4 - Minério de ferro

5 - Outros da indústria extrativa

Fonte: Elaborado pelos autores a partir dos dados IBGE(2014) e Nereus (2014). 
Figura 3. Impacto percentual do efeito estrutura da demanda sobre os postos de trabalho do setor primário, no Brasil para o período 2000-2009

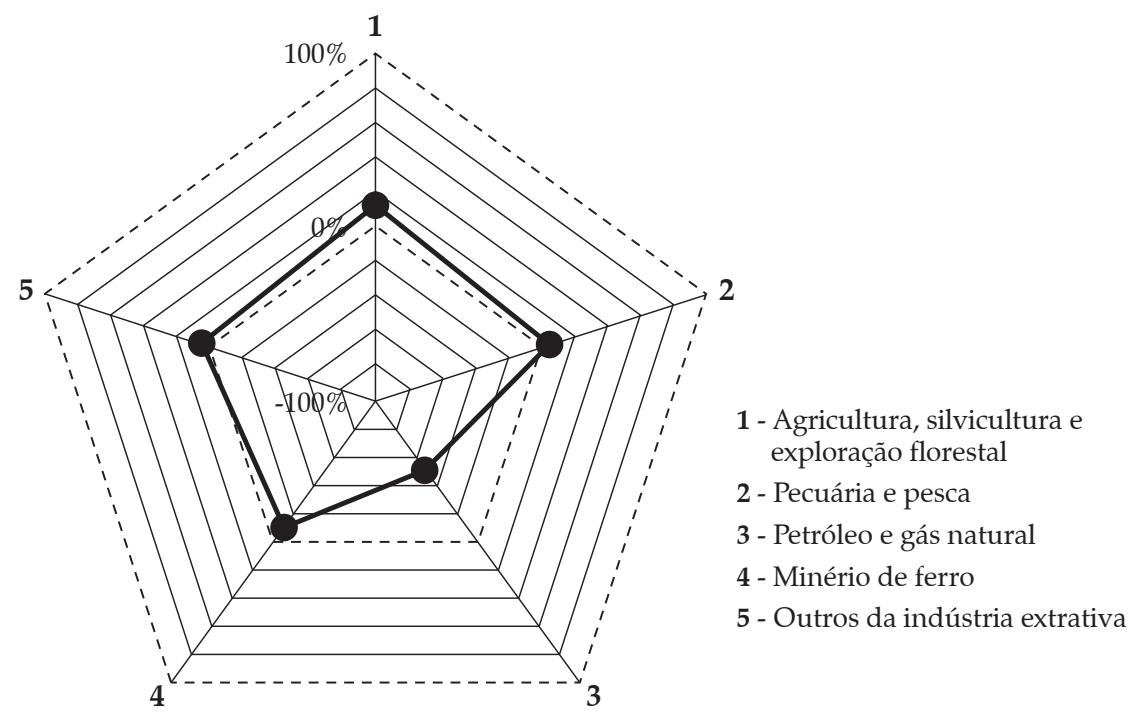

Fonte: Elaborado pelos autores a partir dos dados IBGE(2014) e Nereus (2014).

setores que apresentaram reduções relativas de postos de trabalho devido ao efeito estrutura da demanda final foram os de número 3 e 4 (petróleo e gás natural e minério de ferro), com variação de $-51 \%$ e $-10,7 \%$.

A Figura 4 indica o impacto percentual de empregos entre 2000 e 2009 devido ao efeito volume da demanda. Todos os setores que compõem o setor primário apresentaram variações positivas no volume de emprego causadas pelo que podemos chamar de crescimento da demanda final. O setor de agricultura, silvicultura e exploração florestal contava com 12,16 milhões de vagas de trabalho em 2000 e obteve aumento de 2,65 milhões de vagas de trabalho no período entre 2000 e 2009 , o que equivale a aumento de $21,8 \%$. O setor de pecuária e pesca, com 5,45 milhões de vagas de trabalho em 2000, mostrou aumento de $21,4 \%$. As nove mil novas vagas de trabalho, geradas pelo efeito volume da demanda final, no setor de petróleo e gás, representaram acréscimo de 38,3\% no setor ao final do período, que de início contava com 23,5 mil vagas. Nos setores de minério de ferro (32\%) e outros da indústria extrativa $(22,2 \%)$ também houve criação de vagas de trabalho causada pelo efeito volume da demanda final.

O efeito estrutura da demanda final refere-se à combinação (proporção) do consumo realizado por governo, famílias, exportações e formação bruta de capital. O resultado positivo no impacto sobre o emprego mostra que houve mudança na estrutura da demanda a favor dos subsetores primários, principalmente para os da agropecuária. Isto mostra que a demanda final pode impactar o emprego por modificação da proporção de produtos adquiridos mesmo sem que ocorra crescimento econômico. Considerando-se o crescimento econômico e da renda per capita observa-se o aumento da demanda por produtos com maior elasticidade-renda.

A Figura 5 relaciona a variação percentual liquida do emprego no setor primário, ou seja, o saldo da soma dos efeitos intensidade de emprego, tecnológicos, estrutura da demanda final e volume da demanda final, entre 2000 e 2009. Destaca-se o setor de petróleo e gás e o setor de minério de ferro entre os que apresentaram ganhos percentuais no montante de posto de trabalho com valores de $170,2 \%$ e $95,9 \%$, 
Figura 4. Impacto percentual do efeito volume da demanda sobre os postos de trabalho do setor primário, no Brasil para o período 2000-2009

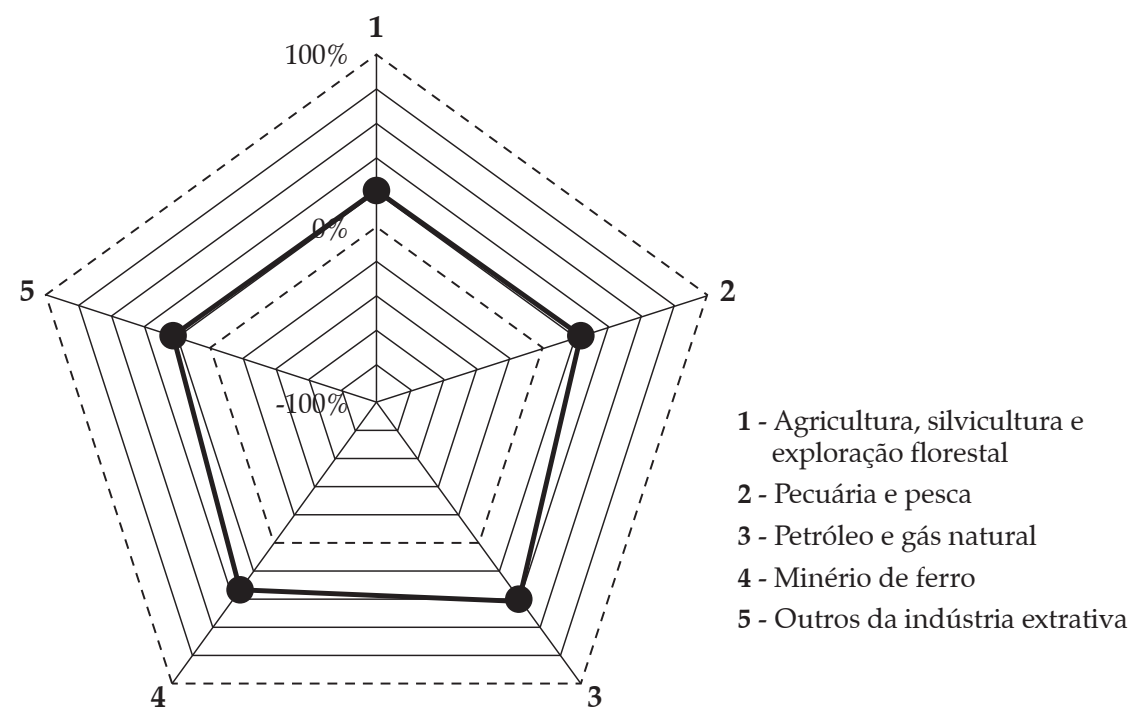

Fonte: Elaborado pelos autores a partir dos dados IBGE (2014) e Nereus (2014).

Figura 5. Impacto percentual do efeito total sobre os postos de trabalho do setor primário no Brasil para o período 2000-2009

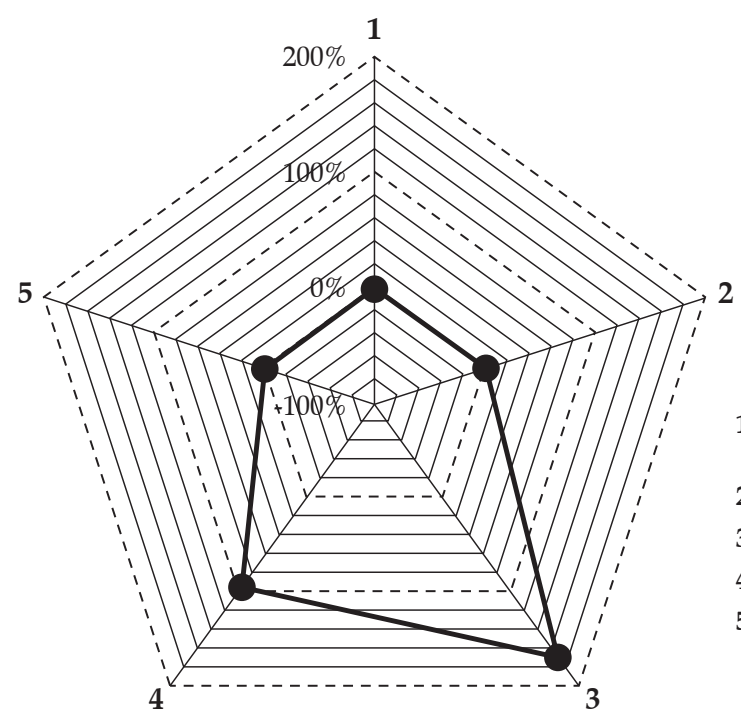

1 - Agricultura, silvicultura e exploração florestal

2 - Pecuária e pesca

3 - Petróleo e gás natural

4 - Minério de ferro

5 - Outros da indústria extrativa

Fonte: Elaborado pelos autores a partir dos dados do IBGE (2014) e Nereus (2014).

respectivamente. O setor de outros da indústria extrativa apresentou aumento de $1 \%$ no montante de vagas de trabalho de 2000 a 2009. Os demais setores tiveram tendência de queda na quantidade de vagas de trabalho. O setor de pecuária e pesca apresentou variação de $-7,4 \%$, seguido pelo setor de agricultura, silvicultura e exploração florestal $(-3,6 \%)$. O resultado final para o setor primário foi uma queda de $-4,3 \%$ na quantidade de postos de trabalho, no período, para o Brasil. 
O efeito volume da demanda final pode ser chamado de crescimento econômico, e o impacto sobre o emprego ocorre por aumento da demanda final e efeitos indiretos sobre os setores da cadeia produtiva, notadamente sobre os subsetores primários que são tradicionais fornecedores de insumos para a economia. Isto explica o efeito percentual homogêneo do volume da demanda final sobre o emprego dos cinco subsetores primários em análise.

É válido destacar que, apesar de não serem representativos em números absolutos, os setores de petróleo e gás natural e minério de ferro se mostraram peculiarmente sensíveis com relação à variação relativa de postos de trabalho, principalmente devido ao efeito tecnológico para petróleo e gás e efeito intensidade de emprego para o de minério de ferro.

\section{Considerações finais}

O presente estudo permitiu demonstrar que, apesar de alguns teóricos afirmarem que a tecnologia gera redução da força de trabalho por meio da substituição do humano por maquinário, o progresso técnico em seu efeito final pode, mesmo considerando a existência de outros fatores que impactem no efeito volume da demanda, levar à criação líquida de postos de trabalho. Porém, diferente dos setores secundário e terciário, para o setor primário tal fenômeno não é observado, indicando a possibilidade de que o progresso técnico leve a uma migração dos postos de trabalho deste setor para os demais.

A análise desagregada dos setores permitiu verificar que a queda no número de postos de trabalho no setor primário é resultado das variações negativas dos setores de agricultura, silvicultura e exploração florestal e pecuária e pesca, dado que os demais setores (petróleo e gás natural, minério de ferro e outros da extrativa) apresentaram variações positivas no montante de vagas de trabalho entre os anos de 2000 e 2009.

Conclui-se que o efeito intensidade de emprego foi o principal causador da destruição de postos de trabalho no setor primário. Apesar de os setores de petróleo e gás natural e minério de ferro apresentarem criação de novas vagas pelo efeito de intensidade de emprego, a representatividade no total dos postos de trabalho não foi suficiente para compensar a destruição de vagas que ocorreu nos setores de agricultura, silvicultura e exploração florestal, pecuária e pesca e outros da indústria extrativa, o que resultou em destruição significativa de postos de trabalho para o total do setor.

Para o efeito tecnológico, todos os setores, exceto minério de ferro, apresentaram variações positivas, o que permite concluir que, no setor primário, o efeito tecnológico contribuiu para a geração de novos postos de trabalho. É válido destacar a influência positiva do efeito tecnológico para o setor de petróleo e gás natural, que apresentou aumento de $140 \%$ nas vagas de trabalho. O efeito estrutura da demanda final mostrou influências inversas ao efeito intensidade de emprego, em que os setores impactados de forma negativa por aquele são justamente os impactados positivamente por este. Destaca-se o desempenho negativo do setor de petróleo e gás natural, cuja explicação pode ser a de que ao longo do período estudado seus produtos passaram a ser substituídos por outros, por motivos de preço e/ou ambientais, uma vez que são amplamente utilizados como insumos para combustíveis. $\mathrm{O}$ efeito volume da demanda final influenciou positivamente a geração de empregos para todos os setores que compõem o setor primário, fenômeno observado também para o setor secundário e terciário.

O efeito líquido final indicou destruição de postos de trabalho apenas para os setores de agricultura, silvicultura e exploração florestal e pecuária e pesca. Apesar de as mudanças percentuais no número de empregos para os setores de petróleo e gás natural e minério de ferro apresentarem valores na ordem de $170 \%$ e $96 \%$, tais variações não foram suficientes para gerar saldo líquido positivo, devido à baixa proporção relativa dos trabalhadores destes setores quando comparados com o número total de empregos no setor 
primário. O resultado final foi saldo de $-773 \mathrm{mil}$ postos de trabalho em termos absolutos, o que equivale a $-4,3 \%$ do total de vagas de trabalho entre 2000 e 2009.

Houve aumento da produtividade do trabalho (efeito intensidade negativo) para o setor primário, o que causou queda do emprego e da capacidade de geração de empregos por unidade de produção. Considerando-se que os efeitos totais observados para os demais grandes setores (indústria e comércio e serviços) foram positivos, pode-se afirmar que tenha havido uma migração dos postos de trabalho do setor primário (principalmente os de agropecuária) para os demais, corroborando os resultados encontrados em Amorim, Coronel e Teixeira (2009).

Novos estudos podem ser realizados buscando verificar se o aumento da produtividade do trabalho leva ao aumento da remuneração média dentro dos setores e migração de pessoas entre os setores primário, secundário e terciário. Além disso, a migração de pessoas entre setores leva à necessidade de requalificação do trabalhador, o que poderia estar na agenda de pesquisa para futuros trabalhos.

\section{Referências}

AMORIM, A. L., CORONEL, D. A. e TEIXEIRA, E. C. A agropecuária na economia brasileira: uma análise insumo-produto. Perspectiva econômica, v. 5, n. 2, p. 1-19, jul/dez 2009. Disponível em: < http://revistas. unisinos.br/index.php/perspectiva_economica/article/ view/4294>. Acesso em: 21 mai. 2014.

BERNARDES, R., BESSA, V. e KALUP, A. Serviços na Paep 2001: reconfigurando a agenda de pesquisas estatísticas inovação. São Paulo em perspectiva, v. 19, n. 2, p. 115-134, abr.jun. 2005.

CACCIAMALI, M. C. e BEZERRA, L. L. Produtividade e emprego industrial no Brasil. Revista brasileira de economia, Rio de Janeiro, v. 51, n. 1, 1997. Disponível em: <http://bibliotecadigital.fgv.br/ojs/index.php/rbe/ article/view/687/8044> . Acesso em: 21 nov. 2013.

COstA, C. C., GUILhoto, J. J. M. e IMORI, D. Importância dos setores agroindustriais na geração de renda e emprego para a economia brasileira. Revista de Economia e Sociologia Rural, v. 51, p. 787-814, 2013.

DE NEGRI, J. A., DE NEGRI, F. e COELHO, D. (Eds.). Tecnologia, exportação e emprego. Ipea, 2006. Disponível em: <http://www.ipea.gov.br/agencia/images/stories/ PDFs/livros/Cap_1.pdf>. Acesso em: 21 nov. 2013.

DIETZENBACHER, E. e LOS, B. Structural decomposition analysis with dependent determinants. In: Conference on Input Output Techniques, 13, 2000, Macerata. Anais Eletrônicos, Macerata, 2000. Disponível em: $\quad<$ http://policy.rutgers.edu/cupr/iioa/iioa.htm > . Acesso em: 30 nov. 2013.

FIGUEIREDO, M. G. Agricultura e estrutura produtiva do estado do Mato Grosso: uma análise insumoproduto. 2003. Dissertação (Mestrado em Economia Aplicada) - Escola Superior de Agricultura Luiz de Queiroz, Universidade de São Paulo, Piracicaba, 2004. Disponível em: <http://www.teses.usp.br/teses/ disponiveis/11/11132/tde-19022004-102552/>. Acesso em: 26 mai. 2016.

FIUZA-MOURA, F. K. et al. Tecnologia e Emprego no Setor de Comércio e Serviços no Brasil entre os Anos de 2000 e 2009. Revista Brasileira de Inovação, v. 15, p. 87-12, 2016.

GUILHOTO, J. J. M. Análise de insumo-produto: teoria e fundamentos. Texto para discussão. Piracicaba: Departamento de Economia, Administração e Sociologia. Escola Superior de Agricultura "Luiz de Queiroz" - USP, 2000.

. e SESSO FILHO, U. A. Estimação da matriz insumo-produto a partir de dados preliminares das contas nacionais. Economia Aplicada, v. 9, n. 2. abr.jun. 2005, p. 277-299.

. e SESSO FILHO, U. A. Estimação da matriz insumo-produto utilizando dados preliminares das contas nacionais: aplicação e análise de indicadores econômicos para o Brasil em 2005. Economia \& Tecnologia, UFPR/TECPAR, ano 6, v. 23, out./dez. 2010.

HAAN, de M. A structural decomposition analysis of pollution in the Netherlands. Economic Systems Research, v. 13, n. 2, p. 181-196, jun. 2001.

HOEKSTRA, R. e BERGH, J. Comparing structural decomposition analysis and index. Energy Economics, v. 25, n. 1, p. 39-64, 2003.

HOEM, A. A decomposition analysis of the emissions of $\mathrm{CO}_{2}$. In: European Congress of the Regional Science Association, 43, 2003, Jyväskylä, Anais Eletrônicos, Jyväskylä, 2003. Disponível em: <www.jyu.fi/ ersa2003/> . Acesso em: 27 out. 2013. 
IBGE. Instituto Brasileiro de Geografia e Estatística. Matriz de insumo-produto: Brasil, 1985/1990-1996. Disponível em: <http://www.ibge.gov.br>. Acesso em: 25 out. 2013.

. Contas Nacionais: Brasil, 2000-2009. Disponível em: <http://www.ibge.gov.br>. Acesso em: 25 out. 2013.

. Sistema de Contas Nacionais, 2009. Disponível em: <www.ibge.gov.br>. Acesso em: 25 out 2013. (Download: banco de dados)

JACOBSEN, H. K. Energy demand, structural change and trade: a decomposition analysis of the Danish manufacturing industry. Economic Systems Research, v. 12, n. 3, p. 319-343, set. 2000.

JESUS, C. M. e ORTEGA, A. C. Território café do Cerrado: transformações na estrutura produtiva e seus impactos sobre o pessoal ocupado. Revista de Economia e Sociologia Rural, v. 49, p. 771-800, 2011.

KATO, J. M. e PONCHIROLLI, O. O desemprego no Brasil e os seus desafios éticos. Revista da FAE, Curitiba, v. 5, n. 3, p. 87-97, 2002. Disponível em: <http://www. unifae.br/publicacoes/pdf/revista_da_fae/v5_n3_ set_out_2002/o_desemprego_no_brasil_e_os_seus_ desafios_eticos.pdf $>$. Acesso em: 07 out. 2013.

KUBOTA, L. C. As Kibs e a inovação tecnológica das firmas de serviços. Economia e Sociedade, Campinas, v. 18, n. 2 (36), p. 349-369, ago. 2009.

KUPFER, D. e FREITAS, F. Análise estrutural da variação do emprego no Brasil entre 1990 e 2001. Boletim de Conjuntura do Instituto de economia da UFRJ, Rio de Janeiro, p. 1-6, mar. 2004.

LEONTIEF, W. Input-Output Economics. 2. ed. New York: Oxford University Press, 1983.

MATTOSO, J. Tecnologia e emprego: uma relação conflituosa. São Paulo Perspec., São Paulo, v. 14, n. 3, jul. 2000. Disponível em: <http://www.scielo. br/scielo.php?script $=$ sci_arttext\&pid $=$ S0102$88392000000300017 \& \operatorname{lng}=\mathrm{en} \& \mathrm{nrm}=$ iso $>$. Acesso em: 07 out. 2013.

MIERNYK, W. H. Elementos de análise do insumo-produto. São Paulo: Atlas, 1974.

NAKATANI-MACEDO, C. D. et al. Decomposição estrutural da variação do emprego nos setores industriais no brasil entre os anos de 2000 e 2009. Revista de Economia Contemporânea, v. 19, p. 235-260, 2015.

PEREIRA, M. Z., BASTOS, S. Q. A. e PEROBELLI, F. S. Análise sistêmica do setor de serviços no Brasil (2005). In: 40ํㅡㄹ Encontro Nacional de Economia - ANPEC, 2012, Porto de Galinhas.

ROSSI, T. e OLIVEIRA, E. A. A. Q. A questão do desemprego no Brasil, 2005. IX Encontro Latino Americano de Iniciação Científica e $V$ Encontro Latino Americano de Pós-Graduação. Disponível em: <http:// biblioteca.univap.br/dados/INIC/cd/inic/IC6\%20anais/ IC6-115.PDF > . Acesso em: 07 out. 2013.

SANDRONI, P. H. R. Novíssimo Dicionário de Economia. 3. ed. São Paulo: Best-Seller (Nova Cultural), 1999. v. 5.000. 750p. Disponível em: <http://docs.fct.unesp. br/docentes/geo/magaldi/GEO_ECON_16/dicionariode-economia-sandroni.pdf>. Acesso em: 29 mar. 2016.

SESSO FILHO, U. A. et al. Decomposição estrutural da variação do emprego no Brasil, 1991-2003. Economia Aplicada, v. 14, p. 99-123, 2010.

WIER, M. e HASLER, B. Accounting for nitrogen in Denmark: a structural decomposition analysis. Ecological Economics, v. 30, n. 2, p. 317-331, ago. 1999.

YMAI, A. K. Decomposição estrutural do emprego e da renda no Brasil: uma análise de insumo-produto - 1990 a 2007. 80 fl. Dissertação (Mestrado em Economia Regional) Universidade Estadual de Londrina. Londrina. 2010. 
